\title{
Development and application of ceramic membrane in oily wastewater treatment
}

\author{
Qianqian Song ${ }^{1, a}$, Liping Qiu ${ }^{1, b^{*}}$, Qi Qiu ${ }^{2, c}$ and Renzhen Cheng1, d \\ ${ }^{1}$ School of Civil Engineering and Architecture, University of Jinan, Jinan 250022, China \\ ${ }^{1}$ School of Environmental and municipal Engineering, Lanzhou Jiao tong University, Lanzhou, \\ 730070, China \\ ª66308490@qq.com, 'lipingqiu@163.com, 'quiuqi_1994@163.com, '965510172@qq.com \\ ${ }^{*}$ Corresponding author:
}

\begin{abstract}
Keywords: ceramic membrane; oily wastewater treatment; filtration mechanism; the combination process of ceramic membrane.

Abstract: Membrane separation technology, as an important water quality safeguards, has been widely studied and applied in water and wastewater treatment, because of its advantages ( low cost, convenient operation, no phase change and no secondary pollution). Compared with organic membrane, the inorganic ceramic membrane with more stable material properties, which can be described as high temperature resistance, acid-alkali resistance and good chemical stability, has more superiority in the complex wastewater, that have the characteristics of strong acidity, alkaline and corrosive, such as oily wastewater. This article summarizes the classification and characteristics of the ceramic membrane, and analyzes its filtration mechanism. The utilization and development of ceramic membrane and its combination process in different types of oily wastewater treatment are discussed. The future development and existing problems to be solved of ceramic membranes is proposed.
\end{abstract}

\section{Introduction}

With the development of industry, the use of oil is increasing. However, due to technical limitations, mismanagement and other reasons, a large number oil products are discharged into the water, resulting in water pollution. Oily wastewater comes from many industries, such as petrochemicals and industrial production, oil extraction, storage and transportation, transportation, mechanical processing, leather, textiles, food, medicine, etc ${ }^{[1-3]}$. Every year, there are 500 1000 tons of oil in the world flowing into the sea through various channels. If the oily wastewater can not be discharged properly, the rivers, lakes and groundwater sources will be contaminated. And the harmful substances in oily wastewater will affect the health of animals, plants and human beings, limit the growth of crops. What more serious is that, the oil accumulated on the surface of the water may be burning, which will causes safety problems. Therefore, the effective treatment of oily wastewater has become a problem that can not be ignored and should be solved urgently. The traditional treatment methods of oily wastewater can be broadly divided into physical, chemical, physical-chemical, and biochemical methods. The membrane process treating oily wastewater can separate the suspended oil and emulsified oil, and also recycle the concentrated oil, which has great significance in environmental governance, oil recycling and water reuse.

Membrane separation technology is a new technology developed in recent 30 years. It is the cross and combination of materials science and separation technique. Membrane separation technology have the advantages of high separation efficiency, convenient operation, compact equipment, no phase and energy conservation to become an important measure to alleviate the shortage of water resources and control environmental pollution. According to the membrane material, the membrane can be divided into two categories: organic and inorganic membrane. Compared with organic membrane, the superiority of inorganic ceramic membrane, as great thermal stability and chemical stability, good resistance to microbial erosion, easy regeneration and cleaning, high mechanical 
strength and long service life $\mathrm{e}^{[4]}$, make it run stably for a long time in harsh conditions, which has a dominant position in the field of wastewater treatment.

\section{General situation of ceramic membrane}

\section{Classification and characteristics of ceramic membrane}

The ceramic membrane is mainly prepared by traditional ceramic materials, such as $\mathrm{Al}_{2} \mathrm{O}_{3}, \mathrm{ZrO}_{2}$, $\mathrm{TiO}_{2}$, and emerging inorganic materials, as cordierite, carborundum, and silicon nitride. According to the different pore size, pressure driven membrane can be divided into microfiltration (MF, average pore diameter of $0.1 \sim 10 \mu \mathrm{m}$ ), ultrafiltration (UF, average pore diameter of $2 \sim 100 \mathrm{~nm}$ ), nanofiltration (NF, average pore diameter of $0.1 \sim 2 \mathrm{~nm}$ ) and reverse osmosis (RO, average pore size of less than $1 \mathrm{~nm})^{[5]}$. As a new technology of rapid development, the superiorities of ceramic membrane are mainly manifested in the following aspects ${ }^{[6-8]}$. (1) Great chemical stability. Ceramic membrane can resist chemical corrosion of acid, alkali, oxidant and organic solvent, and microbial erosion. It can run stably for a long time under harsh water quality. (2) Great thermal stability. The ceramic membrane can withstand high temperatures. It can operate stably at 400 to $800^{\circ} \mathrm{C}$. The highest working temperature of ceramic membrane is $1000^{\circ} \mathrm{C}$. (3) High mechanical strength. The ceramic membrane has intact and reliable structure. There is no membrane breakage during the long-term operation, which reduces the repeated overhaul. (4) Easy cleaning and regeneration. The ceramic membrane can be cleaned by acid, alkali, oxidant, and its combination, and also regenerated by roasting at high temperature. It has high cleaning efficiency, reducing the downtime required for the cleaning. (5) long service life. Due to the above characteristics, ceramic membrane has longer service life, longer replacement cycle, and lower running cost. (6) the pore size distribution is narrow. The pore size distribution of the ceramic membrane is more uniform, causing higher separation efficiency.

\section{Filtration principle of ceramic membrane}

The filtration mechanism of ceramic membrane can be divided into the following three types: (1) Sieving action. The particles, microorganisms, and organic molecules, whose particle size is larger than pore size of membrane, can be entrapped in the membrane surface of ceramic membrane ${ }^{[9]}$. (2) Adsorption. Depend on the Van der Waals' force, chemical bond force, or electrostatic attraction , the contaminants are adsorbed on the membrane surface and the membrane pore, even the particles of small size ${ }^{[10]}$. (3) Bridging. Because of its interaction, the pollutants bridges into a whole body, which is intercepted by ceramic membrane.

The application of microfiltration and ultrafiltration ceramic membrane in oil-water separation mainly bases on the sieving principle. The separation of oil particles mainly depends on the pore size ${ }^{[11]}$. Actually, the oil particles with small diameter can't pass through the larger membrane holes, because of deformation of oil particles under pressure, adsorption and electric charge. This phenomenon should be explained by the principle of membrane phase separation theory. The membrane phase separation technique is that the organic phase (oil phase) in the liquid-liquid dispersion system is separated from the aqueous phase by using lipophilic or hydrophilic properties of the porous membrane (phase separation membrane). The two liquids are not miscible with each other. And when there is differences in the affinity of membrane for different liquid, a certain liquid will form a pure liquid layer with a certain thickness on the surface of the membrane under hydraulic and external forces. The concentration of other liquid forms a gradient with the pure liquid layer to urge the separation of different liquids.

\section{Application of ceramic membrane and its combination process in oily wastewater treatment}

Treatment of oilfield produced water and petrochemical oily wastewater by ceramic membrane

There are a large amount of organic impurities in the oilfield produced water and petrochemical wastewater, which also include suspended oil, emulsified oil and various surfactants in the dissolved state. Membrane technology applied to this kind of wastewater treatment mainly includes microfiltration and ultrafiltration to intercept micro suspended solids, emulsified oil and dissolved oil in sewage. Suspended solids and emulsified oil are intercepted, due to size limitations by membrane. And dissolved oil is intercepted basing on the interaction between the membrane and solute molecules. The stronger the 
hydrophilicity of membrane is, the stronger the ability of retaining free oil is, and the higher the flux of water is. Many domestic and foreign scholars have made a lot of research for this kind of wastewater treatment. M.Ebrahimi adopted ceramic membrane microfiltration and air flotation combined process. In the operating conditions ( $0.2 \mathrm{~m}$ of membrane pore size, $0.1 \mathrm{MPa}$ of TMP, $90 \mathrm{~min}$ of running time), the oil removal rate reached $93 \%$. However, it was worth noting that if the treatment time extended to $120 \mathrm{~min}$, the oil removal rate was only $74 \%^{[12]}$. Therefore, the proper treatment conditions play an important role in the treatment effect. P.Mittal prepared ceramic dynamic membrane by kaolin. Under the condition of $138 \mathrm{kPa}$ of TMP, the oil removal rate reached $93 \%$. And the treatment cost was preferably reduced ${ }^{[13]}$. Shu Li utilized $\mathrm{ZrO}_{2}$ ceramic membrane and auxiliary ultrasound technology to deal with oily wastewater. The oil removal rate was $99.9 \%$. And the time of cleaning was shortened ${ }^{[14]}$. In other words, we can filter the water phase and the oil phase through the ceramic membrane to achieve multiple objectives, as treating oily wastewater, recovering oil, and reusing the industrial waste water.

\section{Treatment of oily wastewater in mechanical processing industry with ceramic membrane}

Lubricating oil used in machining process, emulsified oil of cooling and transmission, oily wastewater in cleaning parts, oily wastewater caused by equipment leakage, and washing wastewater of equipment, containers, and ground in machine workshop, are the main source of oily wastewater in mechanical processing $^{[14]}$. The surfactant contained in this kind of wastewater is combined with highly dispersed mechanical oil to form a stable emulsion oil, which increases the difficulty in the treatment of this kind of wastewater. In early 70s, the $\mathrm{ZrO}_{2}$ dynamic membrane, named Ucarsep inorganic ceramic membrane, was developed. The inorganic ceramic membrane, whose pore size is $0.02 \sim 0.1 \mu \mathrm{m}$, was used for treating cleaning wastewater in machinery processing factory. The results showed that the oil content in the treated liquid was up to the discharge standard. And the concentrated liquid was used as a cycle or as fuel. Superior Planting Inc, as one of the western United States large metal processing factory, created a kind of inorganic ceramic membrane to treat metal cleaning liquid. The results showed that the oil content was reduced from $448 \mathrm{mg} / \mathrm{L}$ to $19 \mathrm{mg} / \mathrm{L}$. After the treatment with inorganic ceramic membrane, the removal rate of emulsified oil in wastewater reached $96 \%{ }^{[15]}$.

\section{Treatment of cold rolled steel emulsion by ceramic membrane}

Cold rolled steel emulsion is a kind of oily wastewater with complex composition. And it mainly composed with mineral oil or vegetable oil, emulsifier and water. Oil content is relatively high, generally about $2 \%-10 \%$. This kind of oily wastewater has a high degree of emulsification. And conventional treatment methods are difficult to meet the state standards for wastewater discharge. The treatment of cold rolling emulsion is a major technical problem that puzzles the steel rolling industry in our country. Zhang Mingzhi applied the inorganic ceramic ultrafiltration membrane in rolling emulsion, and designed the processing device of inorganic ceramic ultrafiltration membrane. The oil content of effluent was average $4.1 \mathrm{mg} / \mathrm{L}$, lower than the national emission standards $15 \mathrm{mg} / \mathrm{L}$. The problem of oil-water separation was solved. The oil sludge pollution was eliminated. And the waste oil was effectively recycled ${ }^{[16]}$.

\section{Treatment of oily wastewater in catering industry with ceramic membrane}

In food industry, oily wastewater mainly comes from oil production, livestock processing and washing, and catering industry, etc. This kind of wastewater contains grease and protein. The content of COD is high. The ceramic membrane was used to recycle alkaline abluent in wastewater from milk industry. The alkaline cleaning wastewater contains oil, fat, protein and so on. And the temperature of this wastewater was as high as $80^{\circ} \mathrm{C}$. After treating by ceramic membrane, the cleaning agent was greatly recycled.

\section{Conclusion and Prospect}

Inorganic ceramic membrane can effectively treat oily wastewater with advantages for no adding chemicals, strong resistance to external factors, and efficiently intercepting organic substances in wastewater. Not only the effective separation of oil and water is achieved, but also the multiple targets of recycling concentrated oil and reusing water resources are realized. There are still many problems that restrict its extensive application and deserve further study and discussion. How to reduce the production cost of ceramic 
membrane? How to improve the separation effect and maintain the stability of membrane flux for a long time? How to modify the surface of inorganic ceramic membrane to reduce membrane fouling? All of these should be the key breakthrough in the preparation and application of ceramic membranes. With the continuous development of science and technology and the increasing attention of the countries all over the world, the development and application of inorganic ceramic membranes will have a bright future.

\section{Acknowledgements}

This work was financially supported by National Natural Science Foundation of China (51678276), Science and technology development projects of Shandong province (2016GSF117012, 2016CYJS07A03-3).

\section{Reference:}

[1] AlFutaisi Ahme, Jamrah Ahmad, Yaghi Basma, et al. Assessment of alternative management techniques of tank bottom petroleum sludge in Oman[J]. Journal of Hazardous Materials, 2007, 141(3): 557-564.

[2] Machín-Ramírez C, Okoh A I, Morales D, et al. Slurry-phase biodegradation of weathered oily sludge waste[J]. Chemosphere, 2008, 70(4): 737-744.

[3] Chen G H, He G H. Separation of water and oil from water in oil emulsion by freeze/thaw method[J]. Separation and Purification Technology, 2003, 31(1): 83-89.

[4] Chen P L, Zhong Z X, Liu F, et al. Cleaning ceramic membranes used in treating desizing wastewater with a complex-surfactant SDBS-assisted method[J]. Desalination, 2015, 365: 25-35.

[5] Van Geluwe S, Braekenl, Van Der Bruggen B. Ozone oxidation for the alleviation of membrane fouling by natural organic matter: a review[J]. Water Research, 2011, 45 ( 12 ) : $3551-3570$.

[6] Zhang X. Preparation science and characterization of hollow fiber ceramic membranes[D]. Hefei: University of Science and Technology of China, 2010.

[7] Lee S J, Dilaver M, Parkpk, et al. Comparative analysis of fouling characteristics of ceramic and polymeric microfiltration membranes using filtration models[J]. Journal of Membrane Science,2013,432: 97-105.

[8] Lee S J, Kim J H. Differential natural organic matter fouling of ceramic versus polymeric ultra filtration membranes [J]. Water Research, 2014, 48: 43-51.

[9] Gao W, Liang H, Ma J, et al. Membrane fouling control in ultrafiltration technology for drinking water production: a review [J]. Desalination, 2011,272 ( $1 / 2 / 3): 1-8$.

[10] Yan Z, Qu F, Liang H, et al. A review on the ultrafiltration membrane pollution and pretreatment technology[J]. Membrane Science and Technology, 2014, 34 ( 4) : 108-114.

[11] Xie M Q, Wei X W. The research in preparation, filtration mechanism and application of ceramic membrane. Shandong Ceramics,2006, 29(6).

[12] Ebrahitni M, Willcrshausen D, Ashaghi S, et al. Investigations on the use of different ceramic membranes for efficient oil-field produced water treatment [J]. Desalination, 2010, 250(3): 991-996. [13] Mittal P, Jana S, Mohanty K. Synthesis of low-cost hydrophilic ceramic-polymeric composite membrane for treatment of oily wastewater[J]. Desalination, 2011, 282(1):54-62.

[14] Shu L, Xing W H, Xu N P. Effect of ultrasound on the treatment of emulsification wastewater by ceramic membranes[J]. China Journal Chemical Engineering, 2007, 15(6):855-860. ( In Chinese)

[15] Xu N P, Xing W H, Wang P. Application and Prospect of inorganic membrane in industrial wastewater treatment [J]. Membrane Science and Technology, 2000, 3(6): 42-45. (In Chinese).

[16] Zhang M Z. Application of inorganic ceramic ultra-filtering film technology in disposal of cold rolling wastewater [J] . Metallurgical Power, 2006, 5:64-66. (in Chinese) 